DOI: $10.1007 / \mathrm{s} 11684-017-0540-9$

Verso: Comparison in executive function in Chinese preterm and full-term infants at eight months

Recto: Yao Feng et al.

RESEARCH ARTICLE

\title{
Comparison in executive function in Chinese preterm and full-term infants at eight months
}

\author{
Yao Feng ${ }^{1, *}$, Hong Zhou ${ }^{1, *}$, Yan Zhang ${ }^{1}$, Anthony Perkins ${ }^{2}$, Yan Wang $(\varangle)^{1, \text { a }}$, Jing Sun $(\varangle)^{2,3, b}$ \\ ${ }^{1}$ Department of Child, Adolescent and Women's Health, School of Public Health, Peking University, Beijing 100191, China; \\ ${ }^{2}$ Menzies Health Institute Queensland, Griffith University, Australia; ${ }^{3}$ School of Medicine, Griffith University, Australia \\ Q4222
}

*Yao Feng and Hong Zhou contributed equally to this study.

Received: January 2, 2017; accepted: March 22, 2017

Correspondence: ${ }^{a}$ wangyan@bjmu.edu.cn; ${ }^{b}$ j.sun@griffith.edu.au

(C) Higher Education Press and Springer-Verlag Berlin Heidelberg 2017

\begin{abstract}
Executive function (EF) is increasingly recognized as being responsible for adverse developmental outcomes in preterm-born infants. Several perinatal factors may lead to poor EF development in infancy, and the deficits in EF can be identified in infants as young as eight months. A prospective cohort study was designed to study the EF in Chinese preterm infants and examine the relationship between EF in preterm infants and maternal factors during perinatal period. A total of 88 preterm infants and 88 full-term infants were followed from birth to eight months (corrected age). Cup Task and Planning Test was applied to assess the EF of infants, and the Bayley Scale of Infant Development (BSID-III) was used to evaluate cognitive (MDI) and motor abilities (PDI) of infants. In comparison with full-term infants, the preterm infants performed more poorly on all measures of EF including working memory, inhibition to prepotent responses, inhibition to distraction, and planning, and the differences remained after controlling the MDI and PDI. Anemia and selenium deficiency in mothers during pregnancy contributed to the differences in EF performance. However, maternal depression, hypertension, and diabetes during pregnancy were not related to the EF deficits in preterm infants. Future research should focus on the prevention of anemia and selenium deficiency during pregnancy and whether supplementing selenium in mothers during pregnancy can prevent further deterioration and the development of adverse outcomes of their offspring.
\end{abstract}

Keywords executive function (EF); preterm infant; working memory, inhibition to prepotent response, inhibition to distraction, planning

\section{Introduction}

A preterm birth is defined as any birth before the completion of 37 weeks of gestation, or fewer than 259 days since the first day of the last menstrual period (LMP) [1]. Preterm birth occurs in $11 \%$ of live births globally, is the second most common cause of child deaths in children under 5 years old, and accounts for $35 \%$ of the 3.1 million annual neonatal fatalities worldwide [1]. Although medical advances have resulted in smaller and lighter preterm infants surviving [2,3] without disabilities and impairments, preterm births can have lifelong effects on the neurological development, attention, and learning of infants and may lead to behavioral problems when these infants reach their school age [4]. Executive function (EF) is increasingly recognized as critical, as preterm-born infants may display poor attention and learning and behavioral problems [4]. Evidence shows that 
deficits in EF can be identified in infants as young as eight months [5]. The prefrontal cortex has an important role in governing the cognitive aspects of EF [6,7]. Brain damage at an early age may affect brain circulation and lead to poor EF. Thus, the early identification and assessment of EF risk factors are critical if detrimental effects in the development of preterm infants are to be reduced $[8,9]$.

EFs are 'associated with higher-order cognitive abilities, that require holding plans or programs in mind until executed (working memory), inhibiting irrelevant action (inhibition), and planning a sequence of actions (planning)' [10]. A number of perinatal and postnatal factors may lead to poor EF development in infancy and persist in school-age children. Perinatal factors associated with maternal hypertension, preeclampsia, and diabetes during pregnancy have profound effects on the physical health of infants, may lead to preterm births, and can affect the cognitive functioning of infants. Hypertension and preeclampsia during pregnancy have been found to be associated with cognitive problems in children aged 4.5 [11], verbal abilities in children aged 10 [12], and mental health problems in children aged 8-14 [13]. Such problems can continue to adulthood [14]. Notably, previous research on the effects of diabetes on neuropsychological outcomes has been inconsistent with only some studies finding significant effects [15]. Research on effects of maternal hypertension or preeclampsia in pregnancy on the neuropsychological development of infants and young children has also been insufficient [15].

Maternal nutritional factors such as anemia and selenium deficiency are commonly present in pregnant women and are associated with preterm birth and psychomotor status $[16,17]$. Few studies reported maternal nutrition in pregnancy as a significant risk factor affecting infant brain development. In Europe and the United States, medical practitioners recommend the intake of selenium at $2 \mu \mathrm{g} / \mathrm{kg} / \mathrm{day}$. Despite previous research [18] reporting that supplementing selenium is not a common practice among Chinese women, selenium intake may prevent or correct mineral deficiency. Selenium deficiencies have also affected the brain development of animals $[19,20]$. Direct assessments on the effects of anemia and selenium on the EFs of preterm infants are unreported. The present study sought to assess whether: (i) any difference exists between preterm and full-term infants in relation to EFs; and (ii) the difference between the EFs of preterm and full-term infants is significant. Perinatal factors relating to maternal hypertension and postnatal nutritional factors (e.g., selenium deficiency) have been shown to be significantly associated with poor EFs in preterm infants.

\section{Materials and methods}

A prospective cohort study was designed for this study. Infants were recruited when their mothers were admitted to the maternal units of Haidian Maternal and Child Health Hospital and Peking University Third Hospital.

\section{Sample}

This study defined preterm infants as infants born before the completion of 37 weeks of gestation who were physically healthy, free from medical complications, genetic diseases, and neurological, hearing, and physical impairments. Eighty-eight preterm infants who met the criteria were recruited. Conversely, full-term infants were defined as infants born between 37-42 weeks of gestation with a birth weight of $2500-4000 \mathrm{~g}$. In this study, the full-term infants had to be physically healthy, and free from medical complications, genetic diseases, and physical and mental impairments. Eighty-eight full-term infants who met the criteria were recruited. Data were collected at Beijing Haidian Maternal and Child Health Hospital and Peking University Third Hospital from December 2012 to November 2014. The Human Research Ethics Committee at Peking University granted ethics approval for the study.

\section{Data collection}

The data of all infants including birth weight, gestation age, and sex were collected when the infants were born, and data on EF, motor and cognitive abilities measured by Bayley Scale of Infant Development were collected when full-term infants were eight months old and preterm infants were at the corrected eight months of age. Maternal information was collected during pregnancy, following the birth of each infant, and when the preterm infant reached the corrected eight months old. A self-reporting questionnaire was used to collect data from the mothers. Biological data were collected from pathological tests conducted by the pathology departments of the hospitals.

1. The EF tasks were based on the working memory, inhibition task and planning task used by Sun et al. [5].

(1) Working Memory and Inhibition Task. This task was used to assess the working memory of infants, their inhibition to prepotent responses, and their inhibition responses to distractions. Infants were seated on the lap of their mother in a quiet test room and were instructed to 'find the toy'. The level of task difficulty was varied by increasing the number of cups (one, two, and three cups) and delay time (0,4, and $10 \mathrm{~s}$ in one-cup task and 0,2 , 
4, and $10 \mathrm{~s}$ in two-cup and three-cup tasks) between hiding the object and its retrieval. Fig. 1 showed the arrangement of the test room and some toys used in the experiment.

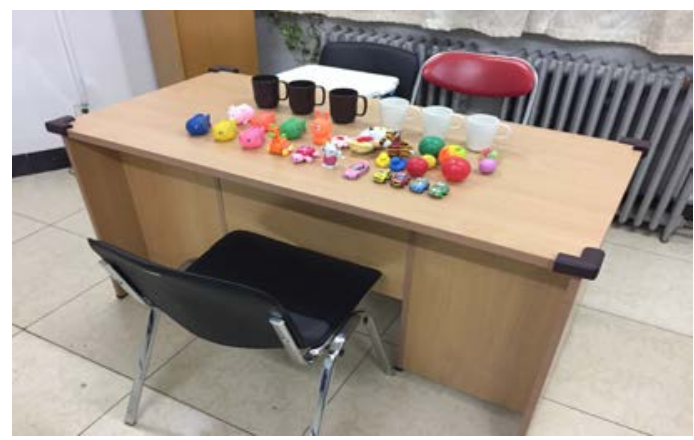

Fig. 1 Arrangement of the test room and toys used in the EF task.

One-Cup Task: A toy was hidden under an opaque cup as the infant watched. Delay time began at $0 \mathrm{~s}$ and was increased to $4 \mathrm{~s}$ and, finally, $10 \mathrm{~s}$. Three trials were conducted for each time delay. If an infant failed to obtain the toy on all three trials at a given time delay or completed the total of nine trials, the one-cup task was terminated and the infant proceeded to the two-cup task.

Two-Cup Task and Three-Cup Task: A toy was hidden under one of two (or three) opaque cups as the infant watched. In three-cup task, the middle cup was only used as a distraction. The toy was always hidden under the cup on the left (L) or right (R) side of the infant and was never hidden under the middle cup. Delay time has four levels $(0,2,4$, and $10 \mathrm{~s})$ and nine trials were conducted for each time delay. The toy was first hidden at location A (e.g., under the left cup) with a $0 \mathrm{~s}$ delay. After the infant had attempted three consecutive trials at location A, the toy was transferred to a new location (e.g., under the right cup), designated as location B. Because the trials were organized and administered in fixed patterns (e.g., the hideout for the toy was, left, left, left, right, right, right, left, left, left at 0 s delay and right, right, right, left, left, left, right, right, right at $2 \mathrm{~s}$ delay, and so on. Table 1), the location A was actually referred to as the hiding position for the toy in the 1st, 2nd, 3rd, 5th, 6th, 8th, and 9th trials at each delay level, and the location B, which represented a new hiding position in contrast to the previous trial, was referred to as the toy hideout in the 4th and 7th trials at each delay level. Once an infant has completed each delay level of the two-cup task trials or failed three consecutive trials at any delay level, he/she then moved on to the three-cup task with a $0 \mathrm{~s}$ delay until the same criteria for termination were met. In the present study, the pattern of changing the hiding pattern was different from the study by Sun et al. [5] because A and B locations were distinct locations and measured different aspects of EF. Location A represented a specific site in which an infant holds the toy information repetitively constant in his/her memory when the hideout for the toy was repeated. Location B was considered to be more difficult for an infant to remember than location $A$ as changing the location would require both working memory to remember the new hiding location and to inhibit a prepotent response, which was established by the repeated action of reaching to location A. Therefore, this task was an innovative modification of the study by Sun et al. where changing the hiding pattern enhances the measurement of both working memory and inhibition to prepotent response as important aspects of EF. The task was therefore conducted within the attention span of the infants and with the tolerance of test time length to maintain the interests of the infants.

Table 1 Infant Working Memory and Inhibition Task

\begin{tabular}{|c|c|c|c|c|c|c|c|c|c|c|}
\hline \multirow{2}{*}{$\begin{array}{l}\text { Number } \\
\text { Cups }\end{array}$} & \multirow{2}{*}{$\begin{array}{l}\text { Delay time between hiding } \\
\text { and reaching (s) }\end{array}$} & \multicolumn{9}{|c|}{ Sequence of the trails in each time delay } \\
\hline & & 1 & 2 & 3 & 4 & 5 & 6 & 7 & 8 & 9 \\
\hline \multirow{3}{*}{1 cup } & 0 & $\mathrm{~L}$ & $\mathrm{~L}$ & $\mathrm{~L}$ & & & & & & \\
\hline & 4 & $\mathrm{~L}$ & $\mathrm{~L}$ & $\mathrm{~L}$ & & & & & & \\
\hline & 10 & $\mathrm{~L}$ & $\mathrm{~L}$ & $\mathrm{~L}$ & & & & & & \\
\hline \multirow{4}{*}{2 cups } & 0 & $\mathrm{~L}$ & $\mathrm{~L}$ & $\mathrm{~L}$ & $\mathbf{R}$ & $\mathrm{R}$ & $\mathrm{R}$ & $\mathbf{L}$ & $\mathrm{L}$ & $\mathrm{L}$ \\
\hline & 2 & $\mathrm{R}$ & $\mathrm{R}$ & $\mathrm{R}$ & $\mathbf{L}$ & $\mathrm{L}$ & $\mathrm{L}$ & $\mathbf{R}$ & $\mathrm{R}$ & $\mathrm{R}$ \\
\hline & 4 & $\mathrm{~L}$ & $\mathrm{~L}$ & $\mathrm{~L}$ & $\mathbf{R}$ & $\mathrm{R}$ & $\mathrm{R}$ & $\mathbf{L}$ & $\mathrm{L}$ & $\mathrm{L}$ \\
\hline & 10 & $\mathrm{R}$ & $\mathrm{R}$ & $\mathrm{R}$ & $\mathbf{L}$ & $\mathrm{L}$ & $\mathrm{L}$ & $\mathbf{R}$ & $\mathrm{R}$ & $\mathrm{R}$ \\
\hline \multirow{4}{*}{3 cups } & 0 & $\mathrm{~L}$ & $\mathrm{~L}$ & $\mathrm{~L}$ & $\mathbf{R}$ & $\mathrm{R}$ & $\mathrm{R}$ & $\mathbf{L}$ & $\mathrm{L}$ & $\mathrm{L}$ \\
\hline & 2 & $\mathrm{R}$ & $\mathrm{R}$ & $\mathrm{R}$ & $\mathbf{L}$ & $\mathrm{L}$ & $\mathrm{L}$ & $\mathbf{R}$ & $\mathrm{R}$ & $\mathrm{R}$ \\
\hline & 4 & $\mathrm{~L}$ & $\mathrm{~L}$ & $\mathrm{~L}$ & $\mathbf{R}$ & $\mathrm{R}$ & $\mathrm{R}$ & $\mathbf{L}$ & $\mathrm{L}$ & $\mathrm{L}$ \\
\hline & 10 & $\mathrm{R}$ & $\mathrm{R}$ & $\mathrm{R}$ & $\mathbf{L}$ & $\mathrm{L}$ & $\mathrm{L}$ & $\mathbf{R}$ & $\mathrm{R}$ & $\mathrm{R}$ \\
\hline
\end{tabular}

$\mathrm{R}$ in the table referred to hiding the toy under the cup on the right side of the infant and $\mathrm{L}$ referred to the left. The bold type of $\mathrm{R} / \mathrm{L}$ in the 4th and 7th trials in each time delay represented changing to a new hiding position that provided a measure of inhibition to a prepotent response. 
Working memory was scored based on the memory of the participant for location A in 2- and 3-cup tasks. A score of " 1 " was awarded each time an infant remembered the location of the toy (i.e., retrieving the toy from the correct location) at location A for both 2-cup and 3-cup tasks. The total number of correct trials was then calculated. Thus, the possible total scores for working memory ranged from 0 to 56, with a higher score indicating a better performance and better working memory.

The scoring for inhibition to prepotent response was based on the infant reaching toward the correct hiding place in 2- and 3-cup tasks and finding the toy when the location shifted from location A to location B. A previous study failed to consider the number of reaches toward location A when assessing inhibitions to prepotent response. The prepotent responses were strengthened when infants respond to a correct location. Thus, this study further modified and developed a new scoring system whereby weighting the inhibition to prepotent responses to comprehensively assess the responses of infants to both location A and location B. Each location had three trials and infants were required to correctly select at least one location, otherwise the trial was terminated.

Scores for inhibition to prepotent response were calculated as follows: (i) if an infant reached toward location $\mathrm{B}$, found the toy, and responded correctly to three consecutive location A trials, then the infant received a score of "3"; (ii) if an infant reached toward location B, found the toy, and responded correctly to two correct location A trials, then the infant received a score of "2"; (iii) if an infant reached toward location B, found the toy, and responded correctly to one location A trial, then the infant received a score of " 1 ". The total score was then divided by the total number of all B trials. Hence, the scores of inhibition to prepotent response ranged from 0 to 3. A higher score indicated a better ability to inhibit prepotent responses.

Inability to inhibit distractions from external stimuli was scored on the 1-cup, 2-cup, and 3-cup tasks at all locations and was based on the ability of an infant to inhibit his/her distraction to the cup covering the toy. To reduce the effect of working memory on inhibition to distraction, scores were only awarded on trials where an infant reached for the hidden location of the toy, but then continued to play with the cup for more than $2 \mathrm{~s}$ rather than retrieving the object. A score of " 1 " was given for each time this incident occurred, which was then transformed into a proportional score through division of the total distraction score by the total number of correct reaching trials, therefore the score of inability to inhibit distraction ranged from 0 to 1 . A higher score denoted the poorer ability of the infant to inhibit his/her distraction by the cups.

(2) Planning Test. Tests by Sun [5] and Willatts [21-23] were used to assess planning ability. The test comprised a progression of three steps with different difficulty levels. The test required the infant to remove an obstacle for the sake of retrieving a toy (i.e., the goal). In step one of the test, the infant was asked to retrieve the toy; however, to do so, the infant had to strategize (e.g., to pull a cloth to get the toy, Fig. 2). In step two of the test, the infant had to remove a transparent barrier and pull a cloth to retrieve the toy (Fig. 3 ). In step three of the test, the infant had to remove a transparent barrier, pull a cloth and then a string to retrieve the toy (Fig. 4).

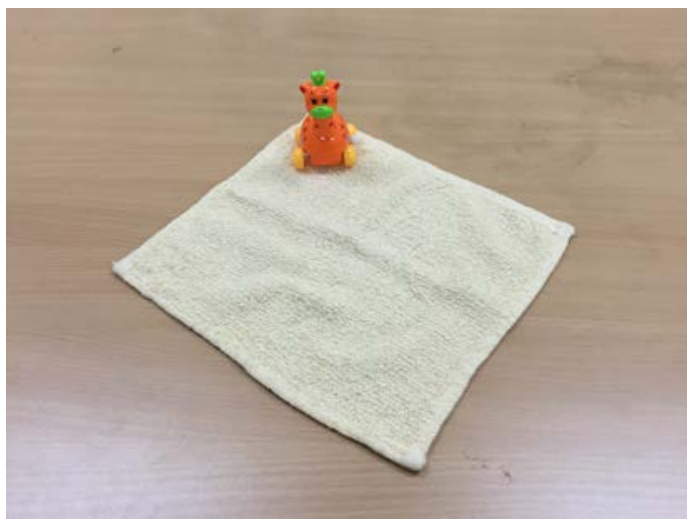

Fig. 2 Step one of the planning task (pull a cloth; retrieve the toy). 


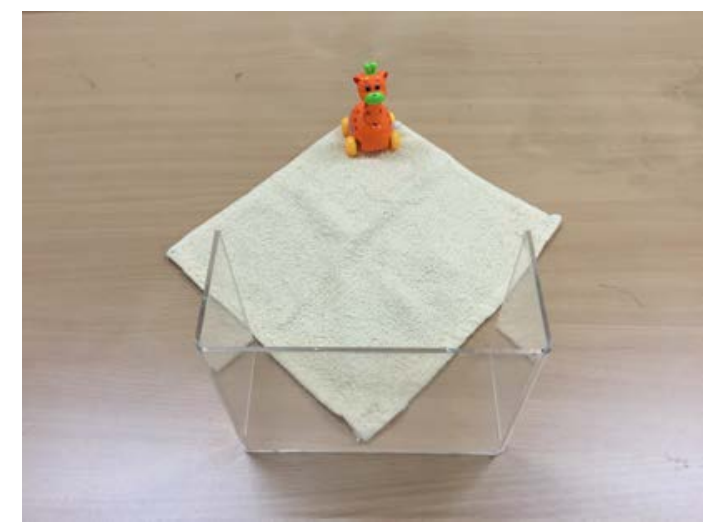

Fig. 3 Step two of the planning task (remove an obstacle; pull a cloth; retrieve the toy).

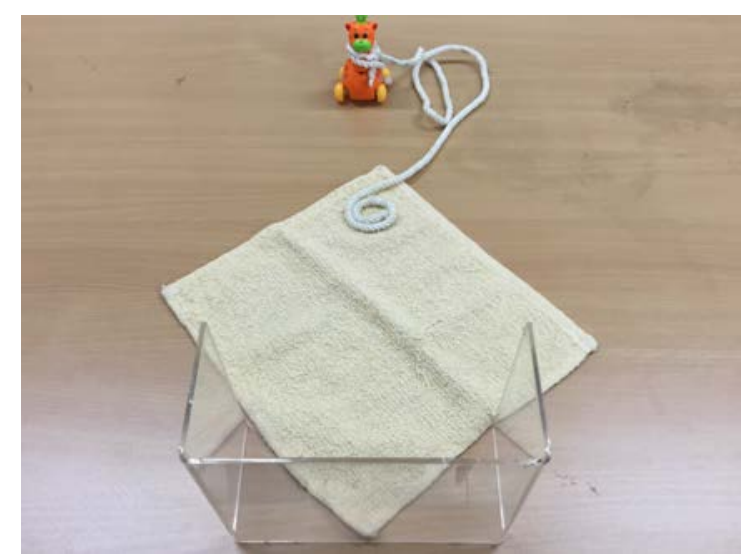

Fig. 4 Step three of the planning task (remove an obstacle; pull a cloth; pull a string; retrieve the toy).

Infants behaviors were assessed at each step in relation to whether their behaviors were goal-directed or not. A score of " 0 " was awarded, if an infant was unaware of the task existence and did not touch or pull the cloth; a score of " 1 " was awarded, if an infant pulled the cloth, but did not fixate his/her eyes on the toy and did not proceed to retrieve the toy; a score of " 2 " was awarded, if an infant pulled the cloth, fixated his/her eyes on the toy and retrieved the toy. The maximum scores that could be obtained for steps one, two, and three of the planning test task were 6, 12 and 18, respectively. A maximum score of 36 could be obtained for the entire test.

Although most studies on older children and adults have suggested the independence of EF on the measures of intelligence; the Bayley Scales of Infant Development III (BSID-III) was also included in the design of this study, as abilities measured on the BSID test, such as cognitive and motor skills, might affect performance on EF measures (e.g., children with poor fine motor skill may have difficulty executing, reaching, and grasping in the EF task). The BSID-III was used to assess cognitive (MDI) and motor abilities (PDI) of infants [24]. The BSID-III was modified to suitably assess infants and toddlers aged 1-42 months. The present study used items suitable for infants aged from 7 months and 15 days to 8 months and 15 days. The BSID-III included 91 cognitive items, 66 fine motor scale items, and 72 gross motor skills items. The items were arranged from easy to difficult and according to age. During the test, an infant was awarded a score of " 1 " for each item that he/she passed, and finally a total composite score for cognitive and motor abilities was calculated.

2. The Edinburgh Postnatal Depression Scale (EPDS) [25,26] was used to measure maternal depression. Mothers completed the EPDS twice, when their infants were three days old and were at the corrected eight months of age. The EPDS consists of 10 items. Each item has four answers that are scored from 0 to 3 . Items 1 and 2 were reverse coded. Scores could range from 0 to 30. A score below or equal to 5 indicated no depression; 6-9 denoted mild depression; and scores above or equal to 10 meant moderate to severe levels of postnatal depression. The EPDS has excellent reliability and validity in Chinese populations [26]. 
3. Maternal information was obtained from medical records and self-report three days after delivery. The disease history during pregnancy, including any diagnoses of hypertension, preeclampsia, and diabetes, and demographic information such as age, education, and family income were all collected.

4. Birth information (i.e., birth weights, gestational ages) was obtained from the medical record of mothers three days after birth. Gestation age was used to classify infants as being preterm or full-term. If an infant was born before the completion of 37 weeks of gestation, then the infant is preterm. If an infant was born between 37 to 42 weeks of gestation, then the infant is full-term.

5. Information on maternal nutrition: Serum was isolated from umbilical cord blood to determine selenium levels. All samples were immediately frozen at $-80{ }^{\circ} \mathrm{C}$ and shipped in batches to the Central Laboratory of Peking University Health Science Center, School of Public Health. Selenium concentration in the serum was measured by Inductively Coupled Plasma Mass Spectrometry (ICP-MS) (DRC-II, Perkin Elmer, USA).

6. Anemia test: A face-to-face interview with 36-week pregnant women was conducted by qualified nurses through a standardized procedure. Venous blood samples $(2 \mathrm{ml})$ were drawn into ethylene diamine tetraacetic acid (EDTA)-treated evacuated tubes and hemoglobin $(\mathrm{Hb})$ concentration was determined immediately. Quality Inspection and Detection was done by the National Center of Clinical Laboratories based on WHO Guidelines [27].

\section{Statistical Analysis}

A bivariate analysis using a chi-square test for the categorical variables and a $t$-test for the continuous variables were used to compare the difference between preterm and full-term infants in relation to demographic variables (i.e., the age and education of mother, family income, and maternal depression) and motor and mental abilities of the infant. Any significant differences for any of these variables were subsequently considered in a Multivariate Variate Analysis of Variance (MANOVA) that compared the EFs of preterm and full-term infants. If any EF differences between preterm and full-term infants were found, then multiple linear regression analyses were conducted to identify any potential factors that could be associated with poor performances in preterm infant group. The following factors were identified: maternal factors (e.g., maternal hypertension, diabetes, anemia, selenium deficiency from pregnancy).

\section{Results}

Table 2 lists the characteristics of the 88 preterm and 88 full-term infants who were followed until they reached eight months of age. Overall, the proportion of male and female infants was similar across preterm and full-term infant groups. The average age of the mothers was 30 years old and the most mothers had more than 12 years of education in both preterm and full-term infant groups. In comparison with mothers of full-term infants, more mothers in the preterm infant group had an annual family income of less than 30000 Chinese Yuan. No significant differences were found in relation to the gender of infants, maternal age, education, family income, and maternal psychological well-being as measured by the EPDS. However, significant differences were observed among the cognitive and motor scales of the BSID-III. Cognitive and motor scores were subsequently controlled to compare the EFs of preterm and full-term infants.

Table 2 Characteristics of the preterm and full-term infant groups

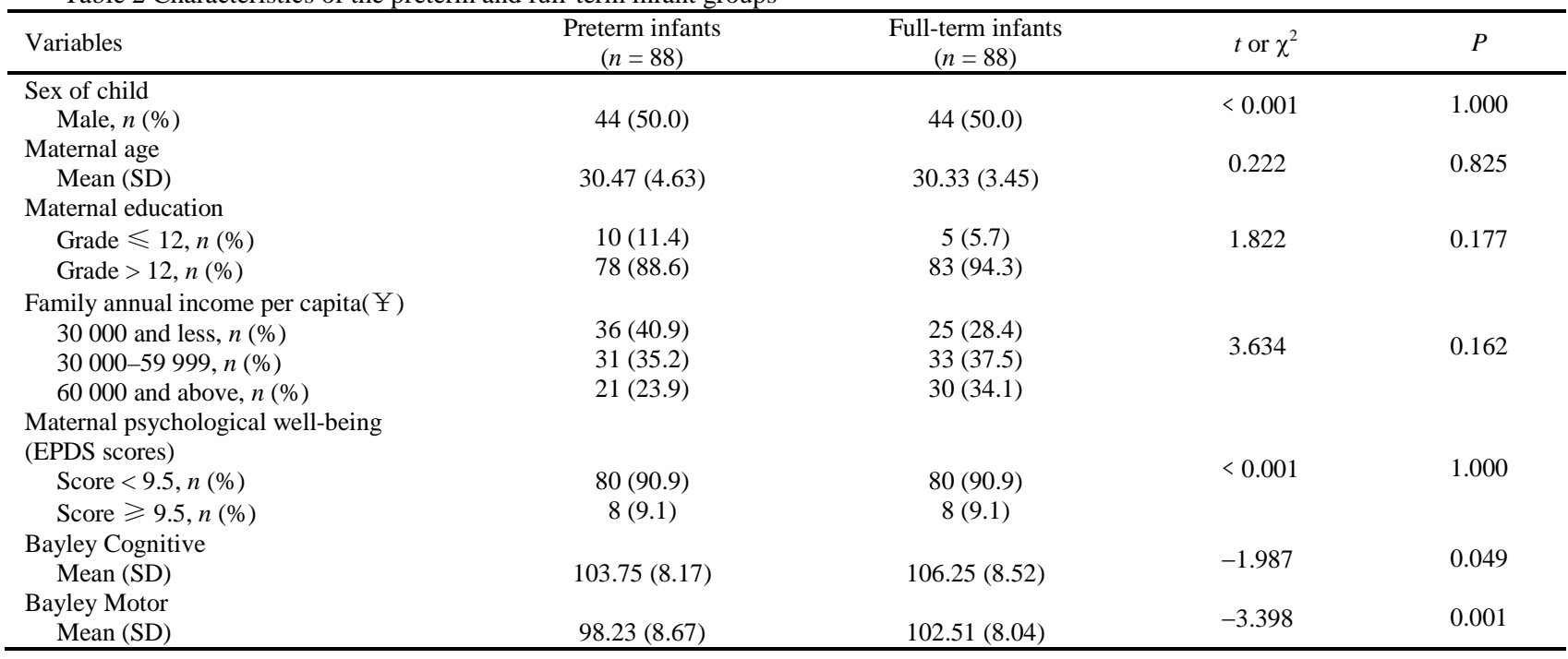


Table 3 shows statistically significant differences across all four components of EF between preterm and fullterm infants. These differences were significant even when BSID-III cognitive and motor abilities were controlled in the MANOVA model.

Table 3 Executive function scores for preterm and full-term infants at 8 months corrected age

\begin{tabular}{|c|c|c|c|c|c|c|}
\hline \multirow{2}{*}{ Variables } & \multirow{2}{*}{$\begin{array}{l}\text { Preterm infants } \\
(n=88)\end{array}$} & \multirow{2}{*}{$\begin{array}{l}\text { Full-term infants } \\
(n=88)\end{array}$} & \multicolumn{2}{|c|}{ Unadjusted model } & \multicolumn{2}{|c|}{ Adjusted model } \\
\hline & & & $F$ & $P$ & $F$ & $P$ \\
\hline 1.Working memory Mean (SD) & $3.80(4.57)$ & $7.98(5.38)$ & 30.833 & $<0.001$ & 23.009 & $<0.001$ \\
\hline 2.Distraction Mean (SD) & $0.39(0.24)$ & $0.29(0.20)$ & 8.978 & 0.003 & 6.173 & 0.014 \\
\hline 3. Inhibition Mean (SD) & $0.35(0.60)$ & $0.80(0.70)$ & 20.527 & $<0.001$ & 15.165 & $<0.001$ \\
\hline 4.Planning Mean (SD) & $11.44(10.60)$ & $17.56(11.67)$ & 13.231 & $<0.001$ & 9.512 & 0.002 \\
\hline
\end{tabular}

Bayley cognitive is associated with planning; $F=18.09, P<0.001$

The differences in the EFs of preterm and full-term infants were significant; however, no EF differences existed between very preterm and preterm infant groups and between very low birth weight and low birth weight infant groups (See Table 4 and Table 5). Maternal hypertension, preeclampsia, and diabetes from pregnancy, insufficient selenium, and anemia were possibly related to poor EF performance rather than gestation age and birth weight. The selenium level, in pregnant mothers was $60 \mathrm{ng} / \mathrm{ml}$, below the Chinese recommended selenium intake of $65-330 \mathrm{ng} / \mathrm{ml}$ [28]. The association of these risk factors in relation to EF was assessed under the regression models (See Table 6 for descriptive information on the maternal selenium and anemia and Table 7 for the results of the regression analyses).

Table 4 Executive function scores at 8 months corrected age for preterm infants 28-31 weeks gestation and 32-36 weeks gestation

\begin{tabular}{|c|c|c|c|c|}
\hline Variables & $\begin{array}{l}\text { 28-31 weeks } \\
\quad(n=9)\end{array}$ & $\begin{array}{c}\text { 32-36 weeks } \\
\quad(n=79)\end{array}$ & $t$ & $\mathrm{P}$ \\
\hline 1.Working memory Mean (SD) & $3.78(5.36)$ & $3.80(4.52)$ & -0.012 & 0.990 \\
\hline 2.Distraction Mean (SD) & $0.40(0.31)$ & $0.39(0.23)$ & 0.202 & 0.840 \\
\hline 3. Inhibition Mean (SD) & $0.45(0.92)$ & $0.34(0.55)$ & 0.352 & 0.733 \\
\hline 4.Planning Mean (SD) & $11.67(10.95)$ & $11.42(10.63)$ & 0.066 & 0.947 \\
\hline
\end{tabular}

Table 5 Executive function scores at 8 months corrected age for low birth weight infants with birth weights of 1000-1499 g and $1500-2499 \mathrm{~g}$

\begin{tabular}{|c|c|c|c|c|}
\hline Variables & $\begin{array}{c}1000-1499 \mathrm{~g} \\
\text { birth weight } \\
\quad(n=11)\end{array}$ & $\begin{array}{l}1500-2499 \mathrm{~g} \\
\text { birth weight } \\
\quad(n=53)\end{array}$ & $t$ & $P$ \\
\hline 1.Working memory Mean (SD) & $3.36(4.06)$ & $4.21(5.02)$ & -0.523 & 0.603 \\
\hline 2.Distraction Mean (SD) & $0.34(0.27)$ & $0.39(0.26)$ & -0.567 & 0.573 \\
\hline 3. Inhibition Mean (SD) & $0.50(0.72)$ & $0.36(0.61)$ & 0.665 & 0.509 \\
\hline 4.Planning Mean (SD) & $10.73(8.58)$ & $10.62(10.92)$ & 0.030 & 0.976 \\
\hline
\end{tabular}

Table 6 Maternal factors of preterm infants

\begin{tabular}{lc}
\hline Variables & $\begin{array}{c}\text { Preterm infants } \\
(n=88)\end{array}$ \\
\hline $\begin{array}{l}\text { Hypertension during pregnancy } n(\%) \\
\text { Yes }\end{array}$ & $23(26.4)$ \\
No & $64(73.6)$ \\
Diabetes $n(\%)$ & $20(22.7)$ \\
$\quad$ Yes & $68(77.3)$ \\
No & \\
Selenium (ng/ml) & $60.20(10.33)$ \\
Mean (SD) & \\
Anemia $n(\%)$ & $66(75.9)$ \\
$\quad$ Yes & $21(24.1)$ \\
No & \\
\hline
\end{tabular}

Table 7 Multiple Linear Regression (Preterm Infants)

\begin{tabular}{|c|c|c|c|c|c|c|c|c|}
\hline \multirow{2}{*}{ Variables } & \multicolumn{2}{|c|}{ Working Memory } & \multicolumn{2}{|l|}{ Distraction } & \multicolumn{2}{|l|}{ Inhibition } & \multicolumn{2}{|l|}{ Planning } \\
\hline & $\mathrm{B}(95 \% \mathrm{CI})$ & $P$ & $\mathrm{~B}(95 \% \mathrm{CI})$ & $P$ & $\mathrm{~B}(95 \% \mathrm{CI})$ & $\mathrm{P}$ & $\mathrm{B}(95 \% \mathrm{CI})$ & $P$ \\
\hline Hypertension & $\begin{array}{l}1.53(-0.66 \text { to } \\
3.71)\end{array}$ & 0.17 & $\begin{array}{l}-0.005(-0.12 \\
\text { to } 0.11)\end{array}$ & 0.94 & $\begin{array}{l}0.22(-0.07 \text { to } \\
0.52)\end{array}$ & 0.14 & $\begin{array}{l}-1.84(-7.25 \text { to } \\
3.56)\end{array}$ & 0.50 \\
\hline
\end{tabular}




\begin{tabular}{|c|c|c|c|c|c|c|c|c|}
\hline Selenium & $\begin{array}{l}-1.99(-4.34 \text { to } \\
0.35)\end{array}$ & 0.02 & $\begin{array}{l}0.10(-0.02 \text { to } \\
0.22) \\
-0.004(-0.009 \mathrm{tc} \\
0.001)\end{array}$ & 0.11 & $\begin{array}{l}-0.13(-0.45 \text { to } \\
0.19) \\
\mathbf{0 . 0 1}(-\mathbf{0 . 0 0 1} \text { to } \\
\mathbf{0 . 0 3 )}\end{array}$ & 0.06 & $\begin{array}{l}-0.64(-6.46 \text { to } \\
5.78) \\
-0.12(-0.36 \text { to } \\
-0.12(-0.36 \text { to } \\
0.13)\end{array}$ & 0.36 \\
\hline Anemia & $\begin{array}{l}3.09(0.86 \text { to } \\
5.32)\end{array}$ & 0.001 & $\begin{array}{l}-0.19(-0.31 \text { to } \\
-0.07)\end{array}$ & 0.002 & $\begin{array}{l}0.46(0.16 \text { to } \\
0.76)\end{array}$ & 0.003 & $\begin{array}{l}3.99(-1.53 \text { to } \\
9.51)\end{array}$ & 0.15 \\
\hline R Square & $15.5 \%$ & & $15.4 \%$ & & $\begin{array}{l}14.3 \% \\
9.5\end{array}$ & & $5.9 \%$ & \\
\hline Adjusted R Square & $10.8 \%$ & & $10.7 \%$ & & $9.5 \%$ & & $0.7 \%$ & \\
\hline ANOVA F & 3.31 & & 3.28 & & 3.00 & & 1.12 & \\
\hline ANOVA P & 0.01 & & 0.02 & & 0.02 & & 0.35 & \\
\hline
\end{tabular}

The bold fonts show statistical significance.

Table 7 shows that the infants of mothers who suffered from selenium deficiency and anemia had significantly lower working memory scores and inhibition to prepotent response compared with infants of mothers who did not suffer from selenium deficiency and anemia. Maternal hypertension, selenium deficiency, and anemia are not associated with planning task performance.

\section{Discussion}

The present study showed significant differences between working memories, inhibitions to prepotent response, inhibitions to distraction, and EF planning of preterm and full-term infants. These results confirmed the findings of previous studies conducted in other countries that preterm infants have poorer EF abilities than full-term infants [5]. Furthermore, the study showed that the performance of preterm infants was worse compared with full-term infants based on EF measures. Given that deficits in EF abilities are linked to later learning and attention problems, such approaches could be used for the early detection of learning and behavioral problems in Chinese preterm-born children. Further studies of school-age children are needed to confirm these findings.

The scores of preterm infants on the cognitive and motor abilities scales of the BSID-III were significantly lower than full-term infants. These results are consistent with previous studies [5], [29]. The MDI and PDI scores on the BSID-III were significantly lower for very preterm infants than full-term infants. Thus, infants with poor cognitive and fine motor skills appear to have difficulties in spatial memory as demonstrated by their inability to find the location of hidden toys, engage in planed sequences of actions, and execute, reach and grasp for items in the EF tasks. However, the differences in EF measures between preterm and full-term infants remained even after controlling for MDI and PDI.

The poorer performance of preterm infants compared with full-term infants led to an investigation of performance factors. Infants with gestational ages of 28-31 weeks did not differ from infants with gestational ages of 32-36 weeks in the EFs. In relation to the working memory, inhibition and planning tasks, differences were also absent between the performances of infants with birth weights of 1000-1499 g and infants with birth weights of 1500-2499 g.

In the present study, most preterm infants did not suffer from medical complications such as asphyxia, hypoxic-ischemic encephalopathy, or intracranial hemorrhages. Such complications can significantly affect the performances of infants in EF tasks. Notably, a previous study examined high-risk preterm infants [5], however, the preterm infants in the present study were healthier and had later gestational ages and higher birth weights. Hence, gestational age, birth weight, and medical complications did not appear to negatively affect the EFs of preterm infants in the present study.

Maternal factors such as hypertension, preeclampsia, and nutrition, including selenium deficiency and anemia, may decrease EF. The present study showed that hypertensive status of mothers did not have any effect on the EF of infants, but reduced working memory and inhibition to prepotent response were associated with insufficient maternal selenium and maternal anemia during pregnancy These findings are consistent with previous studies that identified poor neurocognitive abilities in infants with mothers whose pregnancies were complicated by maternal nutrition factors [30-32].

Tasks that require holding the information in the working memory involve the dorsolateral and ventro-lateral prefrontal cortices [33], while the orbitofrontal cortex regulates tasks that require an ability to inhibit prepotent response [34,35]. The prefrontal lobe is an area of the brain that develops at a late period. Any damage to this 
region during early development could significantly reduce EF performance. The deficits observed in preterm infants across all EF measures (particularly, in infants whose mothers had higher risks of maternal anemia during pregnancy and insufficient selenium) could be associated with the adverse effects that premature births have on the prefrontal cortex, which is still immature and sensitive during this period of development.

Considerable evidence shows that insufficient selenium and anemia during pregnancy significantly disrupts the womb environment and affects the brain development of infants. The present study supports the notion that an unfavorable intrauterine environment may affect healthy fetal brain development, and thus, compromise neuropsychological functioning in early postnatal life [36]. The mechanisms that underpin these relationships are still unknown. Mothers during pregnancy are at high risk of developing selenium deficiency [37]. Selenium is important in brain development and affects brain thyroid concentration, the expression of thyroid-responsive genes, myelinization, and neurotransmitter synthesis [38,39]. Studies have shown that selenium deficiency had adverse effects on neurobehavioral development [40], psychomotor [16], and child development [41]. As a result, a lack of selenium may disrupt the optimal brain development in preterm infants.

Fetal exposure to increased oxidative stress and elevated angiogenic/vasculogenic signaling associated with anemia during pregnancy could affect metabolic substrate homeostasis in the developing iron-deficient brain, possibly contributing to the long-term neurological development of infants [36]. Maternal anemia may have profound and possibly permanent effect on myelinization in the brain, including the prefrontal lobe area because iron deficiency during one growth period (e.g., fetal life) may result in neuroanatomical and neurobehavioral deficits when the brain is rapidly developing [42]. Notably, prefrontal lobe appears to govern EFs [43-46]. Thus, prenatal insults such as anemia could disrupt the optimal development of neural structures that support neuropsychological growth and development.

This study has a number of strengths. The prospective study design and assessment of selenium level in cord blood and anemia assessment during pregnancy constitute an important advantage of this study. Notably, the study is the first to investigate the effects of maternal factors during pregnancy such as anemia and selenium deficiency in the EF of Chinese preterm infants and the first to identify early prenatal risk factors that may lead to poor development outcomes in preterm infants. Consequently, this study is able to closely measure and assess the association between maternal factors and the neurobehavioral factors of infants.

However, the study also has a number of limitations. First, the preterm infants sample only comprised very preterm and preterm infants. High-risk infants and extremely low birth weight infants were not included in the study. Hence, a comprehensive assessment of poor EF causes in preterm infants was not possible. Second, the direct link between EFs and the prefrontal lobe was not assessed, making the association between EFs and the frontal lobes of preterm infants only an inference. Finally, the preterm infants were only followed until they reached eight months in terms of maternal anemia and selenium factors. Therefore, the longer-term effects of maternal anemia and selenium factors on the EFs of preterm infants were not assessed. The present study suggested that maternal anemia in pregnancy and selenium deficiencies are significant factors that may affect the EF development of infants as early as eight months. Future studies need to follow preterm infants to school age to confirm these findings. Prenatal and postnatal health care practices should seek to prevent anemia and selenium deficiency during pregnancy and ensure sufficient provision of iron and selenium to mothers and preterm infants.

This study showed that, preterm infants achieved lower scores in working memory, response inhibition, inhibition distraction, and planning tasks compared with full-term infants. Factors including maternal anemia and selenium deficiencies during pregnancy were significantly related to poor EF in preterm infants. Future research should be conducted on both prenatal and postnatal care, the prevention of anemia and selenium deficiency during pregnancy, and whether supplementing selenium in mothers during pregnancy can prevent further deterioration and the development of adverse outcomes of their offspring.

\section{Acknowledgements}

This study was supported by the National Natural Science Foundation (No.81202216) and Beijing Higher Education Young Elite Teacher Project (YETP0059), People’s Republic of China. We want to thank the research teams from Peking University Third Hospital and Haidian Maternal and Child Health Hospital in Beijing for their orchestration of fieldwork and identification of the study population. We are grateful for the endeavors made by each member in our study, including Yao Feng, Hong Zhou, Yan Wang, Yan Zhang, Fang Ye, Wenxing Bai, Peng Li, Anqi Wang, Xi Wang, Peige Song, Ping Duan, Shusheng Luo, Zhenghong Ren, and Chuyun Kang (Division of Maternal and Child Health, School of Public Health, Peking University), Jing Sun (Menzies Health Institute Queensland and School of Medicine, Griffith University, Australia), Yongmei Chen, Qi Yan, Zhi Li (Haidian Maternal and Child Health Hospital in Beijing), Shan Lu and Yuan Wei (Peking University Third Hospital). 


\section{Compliance with ethics guidelines}

Yao Feng, Hong Zhou, Yan Zhang, Anthony Perkins, Yan Wang, and Jing Sun declare no conflict of interest for this study. The study was approved by the Ethics Committee of Peking University Health Science Center and informed consent was obtained from all patients for being included in the study.

\section{References}

1. Blencowe H, Cousens S, Oestergaard MZ, Chou D, Moller AB, Narwal R, Adler A, Vera Garcia C, Rohde S, Say L, Lawn JE. National, regional, and worldwide estimates of preterm birth rates in the year 2010 with time trends since 1990 for selected countries: a systematic analysis and implications. Lancet 2012; 379(9832): 2162-2172 PMID:22682464 doi:10.1016/S0140-6736(12)60820-4

2. Saigal S, Doyle LW. An overview of mortality and sequelae of preterm birth from infancy to adulthood. Lancet 2008; 371(9608): 261-269 PMID:18207020 doi:10.1016/S0140-6736(08)60136-1

3. Doyle LW. Evaluation of neonatal intensive care for extremely-low-birth-weight infants. Semin Fetal Neonatal Med 2006; 11(2): 139-145 PMID:16406835 doi:10.1016/j.siny.2005.11.009

4. Bayless S, Stevenson J. Executive functions in school-age children born very prematurely. Early Hum Dev 2007; 83(4): 247-254 PMID:16837146 doi:10.1016/j.earlhumdev.2006.05.021

5. Sun J, Mohay H, O’Callaghan M. A comparison of executive function in very preterm and term infants at 8 months corrected age. Early Hum Dev 2009; 85(4): 225-230 PMID:19006652 doi:10.1016/j.earlhumdev.2008.10.005

6. Anderson SW, Damasio H, Tranel D, Damasio AR. Long-term sequelae of prefrontal cortex damage acquired in early childhood. Dev Neuropsychol 2000; 18(3): 281-296 PMID:11385828 doi:10.1207/S1532694202Anderson

7. Stuss DT. Biological and psychological development of executive functions. Brain Cogn 1992; 20(1): 8-23 PMID:1389124 doi:10.1016/0278-2626(92)90059-U

8. Anderson V, Spencer-Smith M, Leventer R, Coleman L, Anderson P, Williams J, Greenham M, Jacobs R. Childhood brain insult: can age at insult help us predict outcome? Brain 2009; 132(1): 45-56 PMID:19168454 doi:10.1093/brain/awn293

9. Diamond A, Churchland A, Cruess L, Kirkham NZ. Early developments in the ability to understand the relation between stimulus and reward. Dev Psychol 1999; 35(6): 1507-1517 PMID:10563738 doi:10.1037/0012-1649.35.6.1507

10. Barkley RA. Behavioral inhibition, sustained attention, and executive functions: Constructing a unifying theory of ADHD. Psychol Bull 1997; 121(1): 65-94

11. van Wassenaer AG, Westera J, van Schie PEM, Houtzager BA, Cranendonk A, de Groot L, Ganzevoort W, Wolf H, de Vries JIP. Outcome at 4.5 years of children born after expectant management of early-onset hypertensive disorders of pregnancy. American Journal of Obstetrics and Gynecology. 2011;204(6):510.e1-.e9. doi: http://dx.doi.org/10.1016/j.ajog.2011.02.032.

12. Whitehouse AJO, Robinson M, Newnham JP, Pennell CE. Do hypertensive diseases of pregnancy disrupt neurocognitive development in offspring? Paediatr Perinat Epidemiol 2012; 26(2): 101-108 PMID:22324495 doi:10.1111/j.13653016.2011.01257.x

13. Robinson M, Mattes E, Oddy WH, de Klerk NH, Li J, McLean NJ, Silburn SR, Zubrick SR, Stanley FJ, Newnham JP. Hypertensive diseases of pregnancy and the development of behavioral problems in childhood and adolescence: the Western Australian Pregnancy Cohort Study. J Pediatr 2009; 154(2): 218-224.e2 PMID:18814885 doi:10.1016/j.jpeds.2008.07.061

14. Tuovinen S, Räikkönen K, Kajantie E, Henriksson M, Leskinen JT, Pesonen AK, Heinonen K, Lahti J, Pyhälä R, Alastalo H, Lahti M, Osmond C, Barker DJ, Eriksson JG. Hypertensive disorders in pregnancy and cognitive decline in the offspring up to old age. Neurology 2012; 79(15): 1578-1582 PMID:23035059 doi:10.1212/WNL.0b013e31826e2606

15. Gerner G, Baron IS. Pregnancy complications and neuropsychological outcomes: A review. Child Neuropsychol 2015; 21(3): 269-284 PMID:24801883 doi:10.1080/09297049.2014.910301

16. Polanska K, Krol A, Sobala W, Gromadzinska J, Brodzka R, Calamandrei G, Chiarotti F, Wasowicz W, Hanke W. Selenium status during pregnancy and child psychomotor development—Polish Mother and Child Cohort study. Pediatr Res 2016; 79(6): 863-869 PMID:26885758 doi:10.1038/pr.2016.32

17. Zhang Q, Ananth CV, Li Z, Smulian JC. Maternal anaemia and preterm birth: a prospective cohort study. Int J Epidemiol 2009; 38(5): 1380-1389 PMID:19578127 doi:10.1093/ije/dyp243

18. Freitas RG, Nogueira RJ, Antonio MA, Barros-Filho AA, Hessel G. Selenium deficiency and the effects of supplementation on preterm infants. Rev Paul Pediatr 2014; 32(1): 126-135 PMID:24676200 doi:10.1590/S0103$\underline{05822014000100019}$

19. Schweizer U, Bräuer AU, Köhrle J, Nitsch R, Savaskan NE. Selenium and brain function: a poorly recognized liaison. Brain Res Brain Res Rev 2004; 45(3): 164-178 PMID:15210302 doi:10.1016/j.brainresrev.2004.03.004

20. Watanabe C, Satoh H. Brain selenium status and behavioral development in selenium-deficient preweanling mice. Physiol Behav 1994; 56(5): 927-932 PMID:7824593 doi:10.1016/0031-9384(94)90325-5

21. Willatts P. Effects of object novelty on the visual and manual exploration of infants. Infant Behav Dev 1983; 6(2-3): 145149 doi:10.1016/S0163-6383(83)80021-6 
22. Willatts P. The stage-IV infant's solution of problems requiring the use of supports. Infant Behav Dev 1984; 7(2): 125134 doi:10.1016/S0163-6383(84)80053-3

23. Willatts P. Stages in the development of intentional search by young infants. Dev Psychol 1984; 20(3): $389-396$ doi:10.1037/0012-1649.20.3.389

24. Bayley N. Bayley scale of infant development: Manual. 2nd ed. San Antonio, TX: The Psychological Corporation; 2006. $374 \mathrm{p}$.

25. Cox JL, Holden JM, Sagovsky R. Detection of postnatal depression. Development of the 10-item Edinburgh Postnatal Depression Scale. Br J Psychiatry 1987; 150(6): 782-786 PMID:3651732 doi:10.1192/bjp.150.6.782

26. Lee DT, Yip SK, Chiu HF, Leung TY, Chan KP, Chau IO, Leung HC, Chung TK. Detecting postnatal depression in Chinese women. Validation of the Chinese version of the Edinburgh Postnatal Depression Scale. Br J Psychiatry 1998; 172(5): 433437 PMID:9747407 doi:10.1192/bjp.172.5.433

27. World Health Organization. Haemoglobin concentrations for the diagnosis of anaemia and assessment of severity. Vitamin and Mineral Nutrition Information System. Geneva: 2011.

28. Ge K. An Overview of Nutrition Sciences. Beijing: People's Medical Publishing House; 2004.

29. Kiselev SY, L'Vova O A, Gliga T, Bakushkina NI, Suleimanova EV, Grishina KI, Baranov DA, Ksenofontova OL, Martirosyan SV. The assessment of neurocognitive functions in premature infants in the first year of life using Bayley Scales. Zhurnal nevrologii i psikhiatrii imeni SS Korsakova / Ministerstvo zdravookhraneniia i meditsinskoi promyshlennosti Rossiiskoi Federatsii, Vserossiiskoe obshchestvo nevrologov [i] Vserossiiskoe obshchestvo psikhiat. 2016;116(4. Vyp 2. Children's neurology and psychiatry):62-7. Epub 2016/07/28. PubMed PMID: 27456723.

30. Heikura U, Hartikainen AL, Nordström T, Pouta A, Taanila A, Järvelin MR. Maternal hypertensive disorders during pregnancy and mild cognitive limitations in the offspring. Paediatr Perinat Epidemiol 2013; 27(2): 188-198 PMID:23374064 doi:10.1111/ppe.12028

31. Koren G. Systematic review of the effects of maternal hypertension in pregnancy and antihypertensive therapies on child neurocognitive development. Reprod Toxicol 2013; 39: 1-5 PMID:23542230 doi:10.1016/j.reprotox.2013.03.006

32. Tuovinen S, Eriksson JG, Kajantie E, Räikkönen K. Maternal hypertensive pregnancy disorders and cognitive functioning of the offspring: a systematic review. J Am Soc Hypertens 2014; 8(11): 832-847.e1 PMID:25455009 doi:10.1016/j.jash.2014.09.005

33. Petrides M. Frontal lobe and working memory: Evidence from investigations of the effects of cortical excisions in nonhuman primates. In: Boller F, Spinnler H, Hendler JA, editors. Handbook of neuropsychology. 9. Amsterdam: Elsevier Science; 1994. p. 59-82.

34. Milner B. Effects of different brain lesions on card sorting. Arch Neurol 1963; 9(1): 90-100 doi:10.1001/archneur.1963.00460070100010

35. Shallice T, Burgess PW. Deficits in strategy application following frontal lobe damage in man. Brain 1991; 114(Pt 2): 727-741 PMID:2043945 doi:10.1093/brain/114.2.727

36. Bastian TW, Santarriaga S, Nguyen TA, Prohaska JR, Georgieff MK, Anderson GW. Fetal and neonatal iron deficiency but not copper deficiency increases vascular complexity in the developing rat brain. Nutr Neurosci 2015;:365-75. 2015;18(8). doi: 10.1179/1476830515Y.0000000037.

37. Mensink GBM, Fletcher R, Gurinovic M, Huybrechts I, Lafay L, Serra-Majem L, Szponar L, Tetens I, VerkaikKloosterman J, Baka A, Stephen AM. Mapping low intake of micronutrients across Europe. Br J Nutr 2013; 110(4): 755-773 $\underline{\text { PMID:23312136 doi:10.1017/S000711451200565X }}$

38. Gu J, Royland JE, Wiggins RC, Konat GW. Selenium is required for normal upregulation of myelin genes in differentiating oligodendrocytes. J Neurosci Res 1997; 47(6): 626-635 PMID:9089211 doi:10.1002/(SICI)10974547(19970315)47:6<626::AID-JNR8>3.0.CO;2-F

39. Watanabe C, Satoh H. Brain selenium status and behavioral development in selenium-deficient preweanling mice. Physiol Behav 1994; 56(5): 927-932 PMID:7824593 doi:10.1016/0031-9384(94)90325-5

40. Yang X, Yu X, Fu H, Li L, Ren T. Different levels of prenatal zinc and selenium had different effects on neonatal neurobehavioral development. Neurotoxicology 2013; 37: 35-39 PMID:23570748 doi:10.1016/j.neuro.2013.04.001

41. Skröder HM, Hamadani JD, Tofail F, Persson LÅ, Vahter ME, Kippler MJ. Selenium status in pregnancy influences children's cognitive function at 1.5 years of age. Clin Nutr 2015; 34(5): 923-930 PMID:25444556 doi:10.1016/j.clnu.2014.09.020

42. Rao R, de Ungria M, Sullivan D, Wu P, Wobken JD, Nelson CA, Georgieff MK. Perinatal brain iron deficiency increases the vulnerability of rat hippocampus to hypoxic ischemic insult. J Nutr 1999; 129(1): 199-206 PMID:9915900

43. Collette F, Van der Linden M. Brain imaging of the central executive component of working memory. Neurosci Biobehav Rev 2002; 26(2): 105-125 PMID:11856556 doi:10.1016/S0149-7634(01)00063-X

44. Lie CH, Specht K, Marshall JC, Fink GR. Using fMRI to decompose the neural processes underlying the Wisconsin Card Sorting Test. Neuroimage 2006; 30(3): 1038-1049 PMID:16414280 doi:10.1016/j.neuroimage.2005.10.031 
45. Rothmayr C, Sodian B, Hajak G, Döhnel K, Meinhardt J, Sommer M. Common and distinct neural networks for falsebelief reasoning and inhibitory control. Neuroimage 2011; 56(3): 1705-1713 PMID:21195194

doi:10.1016/j.neuroimage.2010.12.052

46. Spreng RN, Mar RA, Kim AS. The common neural basis of autobiographical memory, prospection, navigation, theory of mind, and the default mode: a quantitative meta-analysis. J Cogn Neurosci 2009; 21(3): 489-510 PMID:18510452 doi:10.1162/jocn.2008.21029 